\title{
Decline in Life Satisfaction in Old Age: Longitudinal Evidence for Links to Distance-to-Death
}

\author{
Denis Gerstorf and Nilam Ram \\ Pennsylvania State University and Max Planck Institute for \\ Human Development
}

Ulman Lindenberger

Max Planck Institute for Human Development

\author{
Christina Röcke \\ Brandeis University and Max Planck Institute \\ for Human Development
}

Jacqui Smith

University of Michigan and Max Planck Institute for Human Development

\begin{abstract}
Using 12-year longitudinal data from deceased participants of the Berlin Aging Study $(N=414$; age $70-103$ years, at first occasion; $M=87$ years, $S D=8.13$ ), the authors examined whether and how old and very old individuals exhibit terminal decline in reported life satisfaction at the end of life. Relative to age-related decline, mortality-related decline (i.e., distance-to-death) accounted for more variance in interindividual differences in life satisfaction change and revealed steeper average rates of decline, by a factor of 2. By applying change-point growth models, the authors identified a point, about 4 years before death, at which decline showed a two-fold increase in steepness relative to the preterminal phase. For the oldest old (85+ years), a threefold increase was observed. Established mortality predictors, including sex, comorbidities, dementia, and cognition, accounted for only small portions of interindividual differences in mortality-related change in life satisfaction. The authors conclude that late-life changes in subjective well-being are related to mechanisms predicting death and suggest routes for further inquiry.
\end{abstract}

Keywords: selective mortality, terminal decline, successful aging, psychosocial factors, well-being

In the lifespan and gerontological literatures, it has been proposed that trajectories of psychological change at the end of life reflect a combination of age-related, mortality-related, and pathology-related processes (Baltes, 1997; Berg, 1996; Birren \& Cunningham, 1985). The few longitudinal studies in which re-

Denis Gerstorf and Nilam Ram, Department of Human Development and Family Studies, Pennsylvania State University, and Max Planck Institute for Human Development, Berlin, Germany; Christina Röcke, Department of Psychology, Brandeis University, and Max Planck Institute for Human Development; Ulman Lindenberger, Max Planck Institute for Human Development; Jacqui Smith, Institute for Social Research, University of Michigan, and Max Planck Institute for Human Development.

Christina Röcke is now at the Institute of Psychology, University of Zurich, Zurich, Switzerland.

Parts of this article were prepared while Denis Gerstorf was at the Department of Psychology, University of Virginia on a research fellowship awarded by the German Research Foundation (DFG). This article reports data from the Berlin Aging Study (BASE; www.base-berlin.mpg.de). BASE was initiated by the late Paul B. Baltes, in collaboration with Hanfried Helmchen, psychiatry; Elisabeth Steinhagen-Thiessen, internal medicine and geriatrics; and Karl Ulrich Mayer, sociology. Financial support came from the Max Planck Society, the Free University of Berlin, the German Federal Ministry for Research and Technology (1989-1991, 13 TA $011+13$ TA 011/A), the German Federal Ministry for Family, Senior Citizens, Women, and Youth (1992-1998, 314-722-102/9 + 314722-102/9a), and the Berlin-Brandenburg Academy of Sciences' Research Group on Aging and Societal Development (1994-1999).

Correspondence concerning this article should be addressed to Denis Gerstorf, Department of Human Development and Family Studies, Pennsylvania State University, 118 Henderson Building, State College, PA 16802. E-mail: gerstorf@psu.edu searchers have examined such proposals have been focused primarily on questions about the existence of terminal decline in cognitive abilities (i.e., pronounced late-life deterioration as a function of distance-to-death; see Bäckman \& MacDonald, 2006; Bosworth \& Siegler, 2002; Sliwinski, Hofer, Hall, Buschke, \& Lipton, 2003; Small \& Bäckman, 1999). In the present study, longitudinal data is used to compare models of age-related and death-related change in subjective well-being. This is of interest because in cross-sectional research age has typically not been associated with individuals' reported levels of well-being (e.g., Diener, Lucas, \& Scollon, 2006), whereas mortality has been associated with reduced well-being (e.g., Danner, Snowdon, \& Friesen, 2001; Levy, Slade, \& Kunkel, 2002; Maier \& Smith, 1999). Specifically, using 12-year longitudinal data from deceased participants of the Berlin Aging Study (BASE: Baltes \& Mayer, 1999; $N=414 ; M=87$ years and $S D=8.13$ at initial assessment Time 1 [T1]), we (a) contrast age-related and mortality-related trajectories of life satisfaction, a key component of well-being; (b) examine whether, indicative of terminal decline notions, decline in life satisfaction is more pronounced in a time interval closer to death versus further from death, and (c) explore covariates that may underlie interindividual differences in the observed intraindividual changes in life satisfaction.

Starting with seminal work in the 1960s and 1970s (Kleemeier, 1962; Palmore \& Cleveland, 1976; Riegel \& Riegel, 1972; Siegler, 1975), a substantial body of evidence has accumulated showing that low levels of, or pronounced decline on, cognitive abilities including perceptual-motor speed, memory, executive functioning, and crystallized abilities are related to imminent death (Bosworth \& Schaie, 1999; Ghisletta, McArdle, \& Lindenberger, 2006; Jo- 
hansson et al., 2004; Rabbitt et al., 2002; Sliwinski et al., 2003; White \& Cunningham, 1988). These findings are robust after accounting for various physical and medical conditions and appear to be relatively independent of cause of death (e.g., cerebrovascular, cardiac, cancer: Anstey, Mack, \& von Sanden, 2006; Small, Fratiglioni, von Strauss, \& Bäckman, 2003). A diverse set of factors has repeatedly been proposed to potentially account for the noted relationships between cognitive decline and death, ranging from apolipoprotein $\mathrm{E}$ genotype to specific disease mediation, including neurological problems, preclinical and clinical dementia and depression, decreased global biological vitality, reduced vitamin consumption, and fewer cognitively stimulating activities (Hassing et al., 2002; Hofer et al., 2002; Laukka, MacDonald, \& Bäckman, 2006; Sliwinksi, Hofer, Hall, Buschke, \& Lipton, 2003; Wilson, Beck, Bienias, \& Bennett, 2007). Although evidence suggests that (somewhat independent of age and health status) proximity to death may have pervasive effects across a range of measures of cognitive functioning, it is not yet known how many other domains of psychological functioning exhibit associations with distance-to-death.

There are several reasons why subjective well-being may be a candidate for terminal decline. Some researchers argued, for example, that death-related decline is particularly pronounced on measures that are relatively age-insensitive because mortalityrelated effects are less obscured by normative age-graded decline (White \& Cunningham, 1988). A large body of research has suggested that there is a relative, age-graded stability of well-being across adulthood and old age, despite increased risks for social losses and declines in physical health (well-being paradox in old age; Diener et al., 2006; Filipp, 1996; Kunzmann, Little, \& Smith, 2000; Larson, 1978; Mroczek \& Kolarz, 1998). It is conceivable, however, that approaching death may represent an additional burden, making it increasingly difficult to maintain a sense of wellbeing. Another position highlights that well-being may serve as not only a consequence of but also a source for successful aging (Baltes \& Baltes, 1990; Lyubomirsky, King, \& Diener, 2005; Rowe \& Kahn, 1997; Ryff \& Singer, 1998). Specifically, despite a general self-enhancement bias, perceptions of well-being show reliable interindividual and intraindividual variance, allowing subtle differences to be powerful enough to uniquely predict other outcomes of successful aging, including changes in perceptual speed, morbidity, and mortality (Danner et al., 2001; Gerstorf, Lövdén, Röcke, Smith, \& Lindenberger, 2007; Levy et al., 2002; Lyyra, Törmäkangas, Read, Rantanen, \& Berg, 2006; Maier \& Smith, 1999). For example, Mroczek and Spiro (2005) reported that men from the Normative Aging Study who died within 1 year after assessment showed a steeper decline over time in life satisfaction than did those who did not die. These notions suggest that mortality-related decline on measures of well-being might be more pronounced than are normative age gradients and might thereby provide an important qualification to the stability-despite-loss paradox of well-being.

Kleemeier (1962) proposed that terminal decline phenomena involve two phases of change: A preterminal phase of relative stability or gradual decline reflecting rather normative age-graded processes, followed by a terminal phase of pronounced decline likely indexing normative influences as well as an accumulating pathological burden. Recently, change-point growth models have been developed to model multiple phases of change, thereby providing an opportunity to address such notions empirically
(Cudeck \& Klebe, 2002; Hall, Lipton, Sliwinski, \& Stewart, 2000; Wilson et al., 2007; Wilson, Beckett, Bienias, Evans, \& Bennett, 2003). For example, Sliwinski et al. (2006) used such a model to identify a change point around 8 years prior to death when decline in episodic memory steepened dramatically by a factor of 2 relative to the preterminal phase. Establishing whether different phases in mortality-related well-being trajectories could be identified would similarly constitute an important contribution to the literature on terminal decline phenomena.

If indicators of well-being show marked mortality-related decline, one open question is whether the effect is merely indicative of an underlying third variable. Besides typical mortality predictors such as age, sex, and socioeconomic status (SES), one potential set of factors may be medical conditions (e.g., cerebrovascular or cardiac diseases) and physical frailty, which are known to increase mortality risks in old age (Guralnik, 1991). Another potential factor may be pathological burden encompassing preclinical and clinical dementia (Sliwinski et al., 2003). Specifically, recent evidence from the cognitive aging literature suggested that cognitive terminal decline among the very old might largely be attributable to participants in early phases of dementia (Laukka et al., 2006; for discussion of the interplay between well-being indicators and dementia, see Nussbaum, 1997). Finally, mortalityrelated decline in well-being might essentially reflect the effects of low levels of cognitive functioning or cognitive decline and thereby parallel the well-established cognitive terminal decline (Bäckman \& MacDonald, 2006). In the current study, we explored whether mortality-related changes in life satisfaction remain evident when statistically controlling for influences known to be associated with impending death, including age, sex, SES, comorbidities, risk for dementia, and intellectual functioning.

In this study, we extended and qualified insights gained from a long history of theory and research about terminal decline by asking three questions. First, we asked whether interindividual differences in intraindividual change in life satisfaction late in life are best described by chronological age or distance-to-death. To do so, we applied growth curve (e.g., multilevel) modeling to 12-year longitudinal data collected from 414 individuals who died subsequent to their participation in BASE (i.e., age and distance-todeath information was available for each measurement occasion). We evaluated the relative efficiency of age and distance-to-death time models for representing observed changes in life satisfaction.

Second, we explored whether there is evidence for terminal decline in life satisfaction, in that the rate of change is greater closer to death versus further from death. Specifically, we tested whether a model with two phases of linear decline (one preterminal phase and one terminal phase) provided a better representation of the data than a model with a single phase of linear decline over the entire period studied. Given the scarcity of knowledge about the exact location of a transition to a terminal phase of decline, we used empirical tools to test a series of models comparing various transition points to determine whether there is a time interval during which the rate of decline increases in steepness.

Third, we examined associations between the observed interindividual differences in life satisfaction changes and wellestablished mortality predictors, including life period (third age versus fourth age), sex, and SES, as well as comorbidities, risk for dementia, and cognitive functioning. We selected perceptual speed as a measure of cognitive functioning because it represents a powerful and psychometrically sound indicator of (mortality- 
related) cognitive decline in old age (Bosworth \& Schaie, 1999; Ghisletta et al., 2006). In follow-up analyses, we investigated the role of cognitive terminal decline as a time-varying covariate of life satisfaction changes and the seminal Riegel and Riegel (1972) hypothesis of diminished decline among very old individuals relative to old individuals (for a summary of conflicting evidence, see Bäckman \& MacDonald, 2006).

\section{Method}

We used six-wave longitudinal data from deceased participants of the interdisciplinary BASE, collected over 12 years. Detailed descriptions of the variables assessed and procedures used, as well as information about the longitudinal samples and design, were published in Baltes and Mayer (1999), Smith and Delius (2003), and Smith et al. (2002). A brief overview is given below.

\section{Participants and Procedure}

The total cross-sectional BASE sample at T1 $(N=516 ; M=$ 84.92 years, $S D=8.66$, range: $70-103$ years) was stratified by age and sex, with 43 men and 43 women in each of six different age brackets (70-74 years, 75-79 years, $80-84$ years, $85-89$ years, 90-94 years, and 95+ years; born between 1887 and 1922). To obtain this sample, 1,908 individuals drawn from the Berlin city registry were approached for participation. Of those, 516 participants completed a 14-session intensive assessment protocol. Compared with the larger parent sample, the 516-participant sample was found to be positively selected on a number of variables (e.g., younger age, lower 1-year mortality, better physical health and cognitive functioning, and higher well-being), but the amount of selection bias was relatively small and did not exceed 0.50 SD units for any of the variables examined (Lindenberger et al., 1999). In addition, the 516-participant sample was not restricted in heterogeneity and did not exhibit major differences in patterns of covariation among variables (Baltes \& Smith, 1997). Since baseline assessment, extensive effort has been invested in maintaining contact with the participants to avoid voluntary dropout. As expected, given the mean age of the sample at baseline, the primary reason for attrition was mortality. On average, only $10 \%$ of participants have voluntarily dropped out at each measurement occasion, primarily because of poor health.

Information about mortality status and date of death for deceased participants has been obtained from the city registry every 6 months since the study commencement. The update used in these analyses was gathered in June 2005, roughly 15 years after the initiation of BASE, when of the total T1 sample $(N=516)$, only 83 were still alive. Mortality information was missing for 19 participants who had moved out of the Berlin area. The sample considered in our analyses was the 414 BASE decedents. Their average age at death was 91.69 years $(S D=7.19$; range: $74-106$ years). Death occurred an average of 4.84 years $(S D=3.27$; range: 90 days-15 years) after initial assessment (T1) and 2.10 years ( $S D=2.06$; range: 5 days-13 years) after the last assessment in which decedents took part. As is true for any longitudinal inquiry into old age, the number of individuals assessed decreased as the study evolved. Specifically, the following numbers of individuals participated at each measurement occasion: at baseline in 19901993 (T1; $N=414)$, in 1993-1994 (T2; $n=267)$, in 1995-1996 (T3; $n=159)$, in 1997-1998 (T4; $n=88)$, in 2000 (T5; $n=31)$, and in 2004-2005 (T6; $n=2)$. T2, T3, T4, T5, and T6 took place 1.95 years $(S D=0.67), 3.77$ years $(S D=0.62), 5.51$ years $(S D=$ $0.74), 9.00$ years $(S D=0.84)$, and 12.37 years $(S D=1.59)$ after $\mathrm{T} 1$, respectively.

To examine the longitudinal selectivity for the measures under consideration, we used an effect-size metric indicating the degree to which individuals who survived and participated longitudinally differed from the 516-participant sample in BASE at T1 (for details, see Lindenberger, Singer, \& Baltes, 2002). For example, for the 31 deceased participants who provided data for four or more occasions, the total selectivity amounted to $0.16 S D$ units (where $S D$ refers to that of the 516-participant sample) for life satisfaction, $-0.80 S D$ for chronological age, 0.37 $S D$ for SES, $0.00 S D$ for comorbidities, $-0.28 S D$ for dementia, and $0.63 S D$ for perceptual speed. This suggests that higher levels of well-being at T1, younger age, higher SES, and preserved cognitive functioning were associated with subsequently lower mortality and higher participation rates among survivors. Effects of sample selectivity were primarily due to mortality (e.g., life satisfaction: $71 \%$ of the total effect of $0.16 S D$ units) rather than due to dropout for other reasons. The statistical procedures implemented in this study handle this type of nonrandom attrition (see also Data Preparation and Analyses), but we acknowledge that participants who provided the most change (i.e., longitudinal) information represent a positively selected subset of the initial sample.

Trained research assistants and medical personnel carried out all testing in individual face-to-face sessions. With the exception of sessions that involved geriatric medicine, testing took place at the participant's place of residence (i.e., private household or institution). Sessions required an average of $90 \mathrm{~min}$, and when necessary, sessions were split into shorter units of assessment. Over time, the same versions of the questionnaires and tests were administered.

\section{Measures}

Well-being. As a key aspect of well-being, life satisfaction was measured on six occasions with a unit-weighted composite of four items adapted from the Philadelphia Geriatric Center Morale Scale (Lawton, 1975; see also Liang \& Bollen, 1983) and translated into German. This scale has a specific aging focus and primarily assesses cognitive-evaluative rather than emotional aspects of well-being. For practical reasons, with this older population, items were administered in a structured interview format. Each item was read aloud by the research assistants, and participants were asked to indicate how well items described them, on a 5-point Likert-scale ( $1=$ does not apply to me at all, $5=$ applies very well to me). As in previous publications from BASE, we report measures standardized to a $T$ metric $(M=50$ and $S D=10$ at T1), with the total $\mathrm{T} 1$ sample $(N=516)$ serving as the reference. This transformation ensured a common metric across variables while maintaining the psychometric properties of the scores and the longitudinal changes in means and variances. Detailed descriptions of the Philadelphia Geriatric Center Morale Scale Life Satisfaction subscale as used in BASE and its measurement properties can be found in Smith, Fleeson, Geiselmann, Settersten, and Kunzmann (1999).

Background variables. To examine how various mortality predictors were related to interindividual differences in life satisfaction change, we included age, sex, SES, comorbidities, dementia, and perceptual speed in some of our models. Age was used either 
as a continuous variable (grand mean centered at 87 years) or as a dichotomized age group variable $(0=$ young old, $70-84$ years at $\mathrm{T} 1, n=165 ; 1=$ oldest old, $85+$ years at T1, $n=249)$. Sex was coded as follows: $0=$ men $(n=216)$ and $1=$ women $(n=198)$. SES was measured with a unit-weighted composite of (a) equivalent income, defined as the net household income weighted by the number of people sharing the household; (b) occupational prestige, based on a standard rating scale for Germany; and (c) years of education (for details, see Mayer, Maas, \& Wagner, 1999). Comorbidities were indexed by the number of physician-observed medical diagnoses of moderate to severe chronic illnesses, including cardiovascular (e.g., coronary heart disease, stroke) and metabolic diseases (e.g., diabetes mellitus), according to the International Classification of Diseases-9 (World Health Organization, 1992). The diagnoses were determined via clinical examination and were supported by additional blood and saliva laboratory assessments (for details, see Steinhagen-Thiessen \& Borchelt, 1999). To examine potential biases due to dementia, clinical diagnosis of dementia was assessed using a standardized clinical interview and assessment procedure (for details, see Helmchen et al., 1999). In follow-up analyses, we also used an indicator of preclinical dementia over time, as indexed by cohort-specific cutoffs on the Short Mini-Mental State Examination (SMMSE: Klein et al., 1985; range: $0-18$ points; $70-84$ years of age: $<12$ points; $85+$ years of age: $<11$ points), separately at each measurement occasion $(0=$ nondemented, $1=$ demented $)$. Independent clinical diagnoses of dementia in BASE at T1 and T3 indicated sufficient specificity and sensitivity for these cutoffs (for details, see Gerstorf, Herlitz, \& Smith, 2006). Finally, we included perceptual speed, as measured by a unit-weighted composite of the total number of correct responses in the Digit Letter and Identical Pictures tests (for details, see Lindenberger \& Baltes, 1997). The Digit Letter test closely resembles the Digit Symbol Substitution test of the WAIS (Wechsler, 1982). For the duration of the test (3 min), a template with nine digit-letter pairings was presented to the participants. Participants were shown series of digits (six per page) and were required to name the corresponding letter pair, as fast as possible. In the Identical Pictures task, a target figure and five response alternatives were shown on the computer screen (Macintosh SE/30 equipped with a touch-sensitive screen) and participants had to touch the correct response figure (which was identical to the target) as quickly as possible. Up to 32 items were presented, and testing terminated automatically after $80 \mathrm{~s}$.

\section{Data Preparation and Analysis}

To address the research questions of the present study about intraindividual change in life satisfaction, we examined three sets of models: (a) age-related versus mortality-related representations of change, (b) single versus multiple phases of change, and (c) possible correlates of individual differences in change.

Age-related versus mortality-related representations of change. In a first step, we fit two separate growth curve (i.e., multilevel) models of life satisfaction over chronological age and distance-todeath to determine which time dimension provided a better representation of interindividual differences in change over time (McArdle \& Nesselroade, 2003; Singer \& Willett, 2003). In the first model, we used age as the time variable, effectively modeling interindividual differences in how each individual's life satisfaction changed from age 70 years to age $100+$ years. In the second model, we used distance-to-death as the time variable, modeling how life satisfaction changed in relation to impending mortality (i.e., up to 15 years prior to death). Comparing both relative fit and proportion of within-person variance accounted for by these models, we determined which time variable provided a better representation of the data.

Descriptive statistics for life satisfaction over age and distanceto-death are provided in Tables 1 and 2. Figure 1 illustrates the frequencies of observations for the age models in 3-year bins (Panel A) and for the distance-to-death models in yearly bins (Panel B). As can be seen in both panels of the figure, the large majority of the 961 observations available were longitudinal in nature (i.e., 283 , or $68 \%$, of the 414 deceased participants contributed two or more data points). Each participant contributed different longitudinal time segments $\left(M_{\text {observation period }}=1.99\right.$ years, $S D=2.28$; range: $0-12$ years) to an age gradient spanning more than 30 years and a distance-to-death gradient of up to 15 years. In the age models, the information entered was spread relatively

Table 1

Descriptive Statistics for Life Satisfaction as a Function of Age (in Years) at Assessment

\begin{tabular}{|c|c|c|c|}
\hline \multirow[b]{2}{*}{ Age } & \multirow{2}{*}{$\begin{array}{l}\text { Number of } \\
\text { observations }\end{array}$} & \multicolumn{2}{|c|}{ Life satisfaction } \\
\hline & & $M$ & $S D$ \\
\hline 70 & 4 & 49.61 & 11.70 \\
\hline 71 & 7 & 54.00 & 10.18 \\
\hline 72 & 9 & 54.99 & 10.93 \\
\hline 73 & 10 & 50.93 & 8.68 \\
\hline 74 & 18 & 53.59 & 8.33 \\
\hline 75 & 26 & 52.74 & 9.00 \\
\hline 76 & 27 & 50.25 & 7.58 \\
\hline 77 & 19 & 53.00 & 7.76 \\
\hline 78 & 36 & 48.18 & 8.16 \\
\hline 79 & 32 & 48.15 & 9.31 \\
\hline 80 & 44 & 50.64 & 7.16 \\
\hline 81 & 31 & 47.85 & 11.73 \\
\hline 82 & 40 & 51.20 & 8.75 \\
\hline 83 & 36 & 49.22 & 9.53 \\
\hline 84 & 36 & 46.46 & 12.21 \\
\hline 85 & 50 & 49.27 & 10.53 \\
\hline 86 & 44 & 48.79 & 10.97 \\
\hline 87 & 42 & 47.55 & 9.17 \\
\hline 88 & 43 & 47.10 & 11.62 \\
\hline 89 & 40 & 48.08 & 8.83 \\
\hline 90 & 31 & 45.87 & 11.62 \\
\hline 91 & 37 & 44.62 & 8.98 \\
\hline 92 & 34 & 47.79 & 9.56 \\
\hline 93 & 31 & 47.45 & 9.63 \\
\hline 94 & 27 & 41.40 & 12.34 \\
\hline 95 & 44 & 47.54 & 9.72 \\
\hline 96 & 35 & 47.89 & 10.86 \\
\hline 97 & 40 & 48.68 & 9.83 \\
\hline 98 & 20 & 47.18 & 10.03 \\
\hline 99 & 23 & 48.56 & 10.72 \\
\hline 100 & 17 & 42.06 & 13.64 \\
\hline 101 & 16 & 40.09 & 12.62 \\
\hline 102 & 7 & 48.76 & 8.39 \\
\hline 103 & 3 & 47.96 & 15.26 \\
\hline 104 & 1 & 42.44 & \\
\hline 105 & 1 & 35.00 & \\
\hline
\end{tabular}

Note. $\quad N=414$ participants who provided 961 observations. T scores standardized to cross-sectional Berlin Aging Study sample at Time $1(N=$ $516, M=50, S D=10$ ). 
Table 2

Descriptive Statistics for Life Satisfaction as a Function of Distance-to-Death (in Years)

\begin{tabular}{cccr}
\hline & & \multicolumn{2}{c}{ Life satisfaction } \\
\cline { 3 - 4 } Distance-to-death & $\begin{array}{c}\text { Number of } \\
\text { observations }\end{array}$ & $M$ & $S D$ \\
\hline 15 & 1 & 51.16 & \\
14 & 5 & 54.39 & 9.47 \\
13 & 9 & 55.03 & 5.99 \\
12 & 14 & 50.30 & 6.06 \\
11 & 14 & 53.39 & 6.97 \\
10 & 25 & 49.22 & 11.31 \\
9 & 33 & 51.90 & 7.70 \\
8 & 45 & 50.57 & 8.88 \\
7 & 65 & 48.98 & 8.75 \\
6 & 68 & 49.02 & 10.96 \\
5 & 89 & 48.51 & 9.42 \\
4 & 120 & 48.05 & 11.19 \\
3 & 129 & 48.59 & 9.43 \\
2 & 148 & 46.67 & 10.60 \\
1 & 140 & 46.77 & 10.64 \\
0 & 56 & 44.34 & 11.67 \\
\hline
\end{tabular}

Note. $\quad N=414$ participants who provided 961 observations. T scores standardized to cross-sectional Berlin Aging Study sample at Time $1(N=$ $516, M=50, S D=10$ ).

equally across the 3 age decades (70-79 years: $n=188 ; 80-89$ years: $n=406 ; 90+$ years: $n=367)$. In the distance-to-death models, about $50 \%$ of the observations were taken in the last 3 years of life $\left(n_{\text {observations }}=682\right)$ suggesting that parameter estimates are more stable relatively closer to death than further away from death. The intercorrelation of age and distance-to-death was of moderate size $(r=.45, p<.001)$ indicating that there is only partial overlap between the two time dimensions.

Single versus multiple phases of change. Once the time variable was selected, we examined the data for evidence of multiple phases of decline. In particular, we tested models wherein individual trajectories were parameterized either by a single slope parameter that would characterize individual change over the entire study period or by two slope parameters that might capture a systematic shift in the prevailing rate of change-either at a particular age or at a particular distance-to-death. Following procedures similar to those used in studies of cognitive terminal change (Sliwinski et al., 2006; Wilson et al., 2003, 2007), we compared the relative fit of a standard growth model (single slope parameter) with a change-point model (two slope parameters).

More specifically, the first model was parameterized as

$$
l s_{i t}=L_{i}+S 1_{i}\left(\mathrm{time}_{i t}\right)+e_{i t},
$$

where the life satisfaction measure for person $i$ at time $t, l s_{i t}$, is a function of an individual-specific intercept parameter, $L_{i}$, an individual-specific slope parameter, $S 1_{i}$, that captures change over the selected time dimension (age or distance-to-death), and residual error, $e_{i t}$. Interindividual difference in level, $L_{i}$, and slope, $S 1_{i}$, are assumed to be normally distributed around group means, are correlated with each other, and are uncorrelated with the residual errors, $e_{i t}$.

The second model introduced multiphase complexity via a second slope parameter, $S 2_{i}$, and a change point, $k$, that identifies when in time individuals move from one phase of change to another (e.g., the point in time when the terminal phase begins) The model was parameterized as

$$
\begin{aligned}
l s_{i t}= & L_{i}+S 1_{i}\left(\mathrm{time}_{i t}\right)+S 2_{i}\left(\mathrm{time}_{i t}\right)+e_{i t}, \\
& \text { if time }{ }_{i t} \leq k, \text { then } S 2_{i}=0, \text { and } \\
& \text { if time } i t \\
& \geq k, \text { then } S 1_{i}=0
\end{aligned}
$$

for all $t$. As before, interindividual differences in the second slope parameter, $S 2_{i}$, are assumed to be normally distributed around a group mean, are correlated with the other interindividual parameters, $L_{i}$ and $S 1_{i}$, ${ }^{1}$ and are uncorrelated with the residual errors, $e_{i t}$.

Of interest was (a) whether there was evidence for multiple phases of decline (i.e., better overall fit to the data for a changepoint model than for the singe-phase model) and (b) if so, at what age or distance-to-death does the change point, $k$, occur?

Exploring interindividual differences in change. In the final set of analyses, we examined how various time-invariant interindividual difference measures (age, sex, SES, comorbidities, dementia, and perceptual speed) were related to interindividual differences in intraindividual change in life satisfaction. More specifically, time-invariant predictors were included as predictors of interindividual differences in the level and slope parameters describing intraindividual change of life satisfaction. Details of the final model are presented below. In an additional step, we also explored whether change in life satisfaction relates to change in preclinical dementia. To do so, we included a time-varying indicator of preclinical dementia in our models and examined the intercorrelations between change in life satisfaction and change in preclinical dementia.

Models were fit to the data with SAS (Proc Mixed; Littell, Miliken, Stoup, \& Wolfinger, 1996). Incomplete data were treated as missing at random (Little \& Rubin, 1987). Results are presented below, in stepwise fashion, with later analyses having been informed by earlier ones.

\section{Results}

\section{Comparing Age-Related and Mortality-Related Changes in Life Satisfaction}

To examine age-related and mortality-related changes in life satisfaction, we proceeded in two steps. As a preliminary check, we estimated the relative amount of between-persons and within-person variance by considering models that allowed random effects for only the intercept (see Mroczek \& Spiro, 2003). The intraclass correlation revealed by these models was .59 , suggesting that $59 \%$ of the total variation in life satisfaction was between-persons variance and that the remainder $(41 \%)$ was within-person variation. This suggests that although between-persons differences accounted for the majority of

\footnotetext{
${ }^{1}$ Note that the slope $=0$ constraint in Equations 2 and 3 were used so that within person, for any given occasion, only $S 1_{i}$ or $S 2_{i}$ (or neither, i.e., at the intercept) were contributing to the estimated outcome. Both could be nonzero. We used one of the specifications outlined in Cudeck and Klebe (2002), but the model is a parallel representation to the spline or piecewise models given in Singer and Willet (2003) and Bryk and Raudenbush (1992), except that the intercept term in the model we fit is located at the change point rather than at $t=0$, as is the case in some of the other models mentioned in the texts.
} 
A

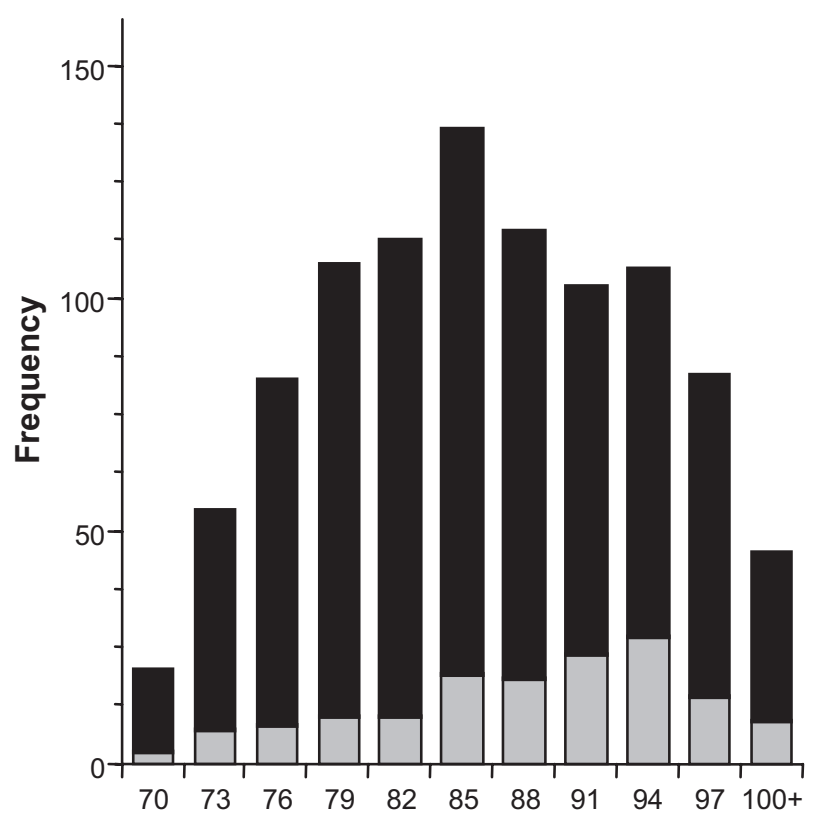

B

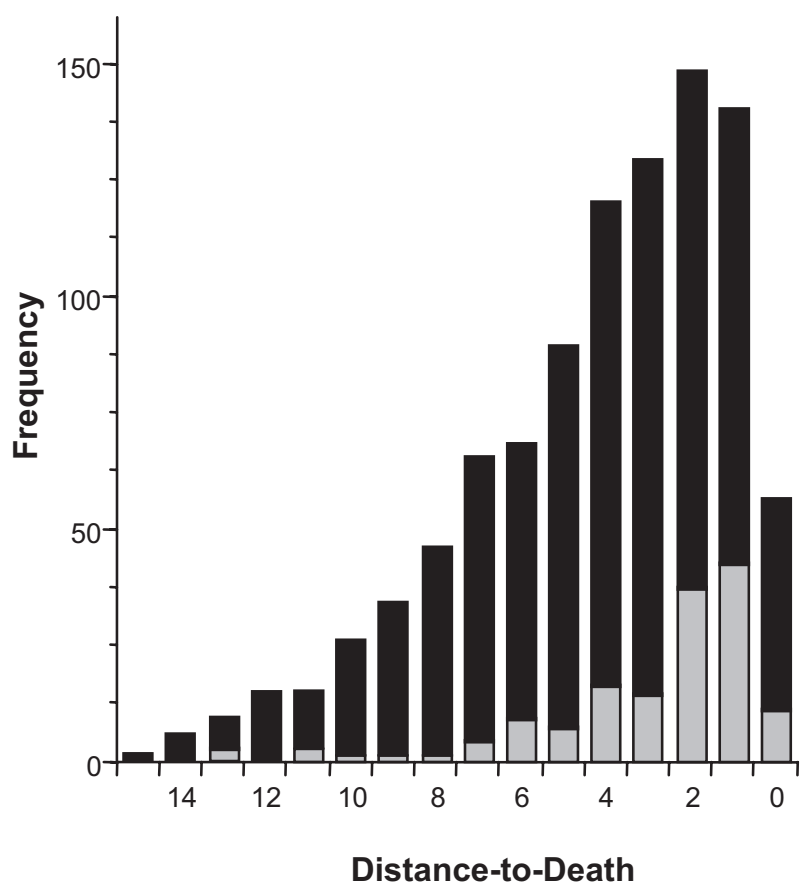

Chronological Age

longitudinal observation

single observation

$N=414$ participants and 961 observations

Figure 1. Frequency of observations (total number) in the Berlin Aging Study in relation to chronological age in 3-year bins (Panel A) and distance-to-death in yearly bins (Panel B). The 414 participants provided 961 observations in total. Of these observations, the large majority was longitudinal in nature. In the age models, observations were spread relatively equally across the three age decades (70-79 years: $n=188 ; 80-89$ years: $n=406$; and $90+$ years: $n=367$ ). In the distance-to-death models, more than $70 \%$ of the observations were taken in the last 5 years prior to death $\left(n_{\text {observations }}=682\right)$.

variability, there also was substantial variability within persons over time. Given this indication that there was indeed intraindividual variation to model, we proceeded to evaluate whether age or distanceto-death was the most efficient dimension to model within-person change in life satisfaction over time. Table 3 summarizes the mean estimates and variance estimates as well as relative model fit indices of both age and distance-to-death growth curve models.

Two criteria were used to identify which time dimension provided a better description of the data: relative overall model fit and relative proportion of variance explained. In terms of relative model fit, nonnested model comparisons indicated that the distance-to-death model (Akaike information criterion [AIC] $=$ $6,854 ;-2 \log$ likelihood $[-2 \mathrm{LL}]=6,842)$ fitted the data better than did the counterpart age models $(\mathrm{AIC}=6,880 ;-2 \mathrm{LL}=$ $6,868)$. We also examined the explained proportion of withinperson variance (i.e., pseudo $R^{2}$ ) captured by each time metricalternatively conceptualized as the proportional reduction of prediction error (Snijders \& Bosker, 1999). Specifically, for each model, we calculated the change in pseudo $R^{2}$ that resulted when either age or distance-to-death was added to the within-person (Level 1) portion of the model. ${ }^{2}$ In the age model, the time variable contributed an additional .077 of explained variance (i.e.,
$\Delta$ pseudo- $R^{2}$ ) to that portion of variance explained by an interceptonly model. In contrast, when distance-to-death was used as the time dimension, the change in pseudo $R^{2}$ was .168 . It was also noted that the inclusion of both time metrics did not further increase the explained variance. In sum, on the basis of the relative overall model fit and proportion of explained variance, it appears that distance-to-death, as a time dimension on which to track longitudinal change, provides a more efficient description of change in life satisfaction in this sample than does chronological age.

${ }^{2}$ Following the general framework outlined by Snijders and Bosker (1999, pp. 99-105), we calculated the explained proportion of withinperson variance as

$$
\Delta \text { pseudo- } R^{2}=1-\left[\sigma_{e(u)}^{2} / \sigma_{e(c)}^{2}\right],
$$

where $\sigma_{e(u)}^{2}$ is the residual within-person variance obtained from an unconditional or intercept-only model (for our data $=42.71$ ) and $\sigma_{e(c)}^{2}$ is the parallel term from the conditional model that includes the time variable, either age or distance-to-death (for our data, 39.44 and 35.53, respectively). 
Table 3

Growth Models Over Chronological Age and Distance-to-Death for Life Satisfaction

\begin{tabular}{lcc}
\hline & \multicolumn{2}{c}{ Life satisfaction } \\
\cline { 2 - 3 } \multicolumn{1}{c}{ Effect } & Age & Distance-to-death \\
\hline \multicolumn{3}{c}{ Fixed effects estimates } \\
Intercept & $49.01(0.46)^{* * * *}$ & $45.34(0.62)^{* * * *}$ \\
Slope & $-0.33(0.05)^{* * * *}$ & $-0.75(0.10)^{* * * *}$ \\
\hline
\end{tabular}

Random effects estimates

$\begin{array}{llc}\text { Variance of } & 57.63(6.84)^{* * *} & 89.48(11.19)^{* * *} \\ \text { intercept } & 0.05(0.07) & 0.37(0.24)^{\dagger} \\ \text { Variance of slope } & 0.58(0.37) & 3.87(1.46)^{* *} \\ \begin{array}{l}\text { Covariance } \\ \text { intercept, slope }\end{array} & 39.44(2.49)^{* * *} & 35.53(2.64)^{* * *} \\ \text { Residual variance } & \end{array}$

Goodness-of-fit indices

$\begin{array}{lll}\text { AIC } & 6,880 & 6,854 \\ -2 \mathrm{LL} & 6,868 & 6,842\end{array}$

Note. $\quad N=414$ participants who provided 961 observations. T scores standardized to cross-sectional Berlin Aging Study sample at Time $1(N=$ $516, M=50, S D=10)$. Standard errors are in parentheses. AIC = Akaike information criterion; $-2 \mathrm{LL}=-2 \log$ likelihood, relative model fit statistic.

${ }^{\dagger} p=.068 .{ }^{* *} p<.01 .^{* * *} p<.001$.

On average, the age model shows significant but relatively minor age-associated decline $(-0.33 \mathrm{~T}$-score units per year). In contrast, decline in the distance-to-death model was more pronounced: Relative to the age model, decline was steeper by a factor of 2.3 (-0.75 T-score units per year). Figure 2 contrasts the average amount of decline observed over age and distanceto-death. This figure illustrates the finding that, on average, life satisfaction remains relatively stable with advancing age (Panel A) but exhibits considerable decline when viewed in relation to individuals' proximity to death (Panel B).

To examine whether the noted mortality-related decline differs by age group, we introduced a dichotomized age group variable into our models to compare life satisfaction decline between the young-old (70-84 years at T1) and the oldest old (85+ years at T1). Our findings indicated that, compared with the age model, the young-old showed somewhat stronger decline on life satisfaction with approaching death (fixed effects of the slope $=-0.54, S E=0.12 ; p<.001$ ). However, the oldest old were found to show an even steeper rate of decline that was approximately double that of the young-old (fixed effects of the slope $=-1.12, S E=0.21 ; p<.001$ ). In contrast, the age model of life satisfaction did not reveal evidence for more pronounced decline among the oldest old $(p>.10)$. In sum, our analyses suggest steeper decline in life satisfaction during the last years of life among very old individuals relative to the young-old. This is contrary to the Riegel and Riegel (1972) hypothesis of diminished terminal decline in late senescence.

\section{Applying Change-Point Models to Mortality-Related Decline in Life Satisfaction}

Having determined that the distance-to-death time dimension provides for a better fit to the BASE data, we proceeded to examine whether and in which circumstances multiple phases of change (i.e., preterminal and terminal decline phases) could be incorporated. In fitting the change-point model described above, we found that the variance terms, capturing interindividual differences within each phase of change, became nonsignificant. Thus, we considered various possible models wherein the variances in either phase were fixed to zero, eventually settling on a model with no interindividual differences in the preterminal phase (zero variance in $S 1_{i}$ ) but with interindividual differences in the terminal phase (significant variance in $S 2_{i}$ ). Constraining the model in this manner then allowed us to estimate and fit a set of change-point models in which $k$, the point of transition between phases, was successively varied from 10 years to 1 year prior to death by increments of roughly 1-month units (1/10 of years). Our intent was to identify empirically the optimal location of the change point, $k$, as indicated by the model with the best overall fit (i.e., lowest log-likelihood, see Wilson et al., 2003, 2007). The best fitting change-point model, under the nonzero variance constraint, was one wherein the change point was located 4 years prior to death. Figure 3 shows the model-implied means for the optimal changepoint model, indicating that the rate of decline was twice as steep during the terminal phase $(-1.16 \mathrm{~T}$-score units per year) than during the preterminal phase $(-0.59 \mathrm{~T}$-score units per year; also see Table 4$)$.

Although optimal, this model did not fit significantly better than models with change points located anywhere in the intervals ranging from 1.5 years to 6.5 years in distance-to-death. Stated differently, the standard error of the change-point location only allowed us to isolate the general time frame during which a transition to a terminal phase of decline might occur (i.e., $4 \pm 2.5$ years prior to death). Regardless of the exact location, however, it is clear that models including change point and two phases of change fit the data significantly better than a single-phase model did. For example, a two-phase model with a change point 4 years prior to death $(-2 \mathrm{LL}=6,832)$ described the structure of intraindividual changes in life satisfaction better than did a single-phase model covering the complete 15 -year period ${ }^{3}(-2 \mathrm{LL}=6,842$; $\Delta-2 \mathrm{LL}=10, \Delta d f=1)$. Comparisons among similarly structured age-based models revealed no evidence for a shift to a more pronounced decline anchored to chronological age ${ }^{4}$ (e.g., age 85 years as change point: $\Delta-2 \mathrm{LL}=1.4$ ).

\section{Exploring Potential Factors Underlying Mortality-Related Decline in Life Satisfaction}

In the final set of analyses, we introduced a variety of timeinvariant covariates in the model and explored their relationships

\footnotetext{
${ }^{3}$ Consistent with our finding of increased steepness of decline prior to death, a model specifying linear and quadratic change in life satisfaction over distance-to-death was found to fit our data only very slightly better $(-2 \mathrm{LL}=6,840)$ than a model with linear change only $(-2 \mathrm{LL}=6,842)$. However, the two-phase model with a change point 4 years prior to death still provided better relative model fit than this single-phase model ( $\Delta-$ $2 \mathrm{LL}=8)$. We also explored quadratic trends over chronological age, but these were not significantly different from zero (neither with nor without random effects)

${ }^{4}$ This also suggests that age-related change was not considerably different between the first 15 years and the second 15 years of the 30-year age range, thereby making it less likely that differences in span between chronological age (30 years) and distance-to-death (15 years) have been a major factor underlying our results.
} 

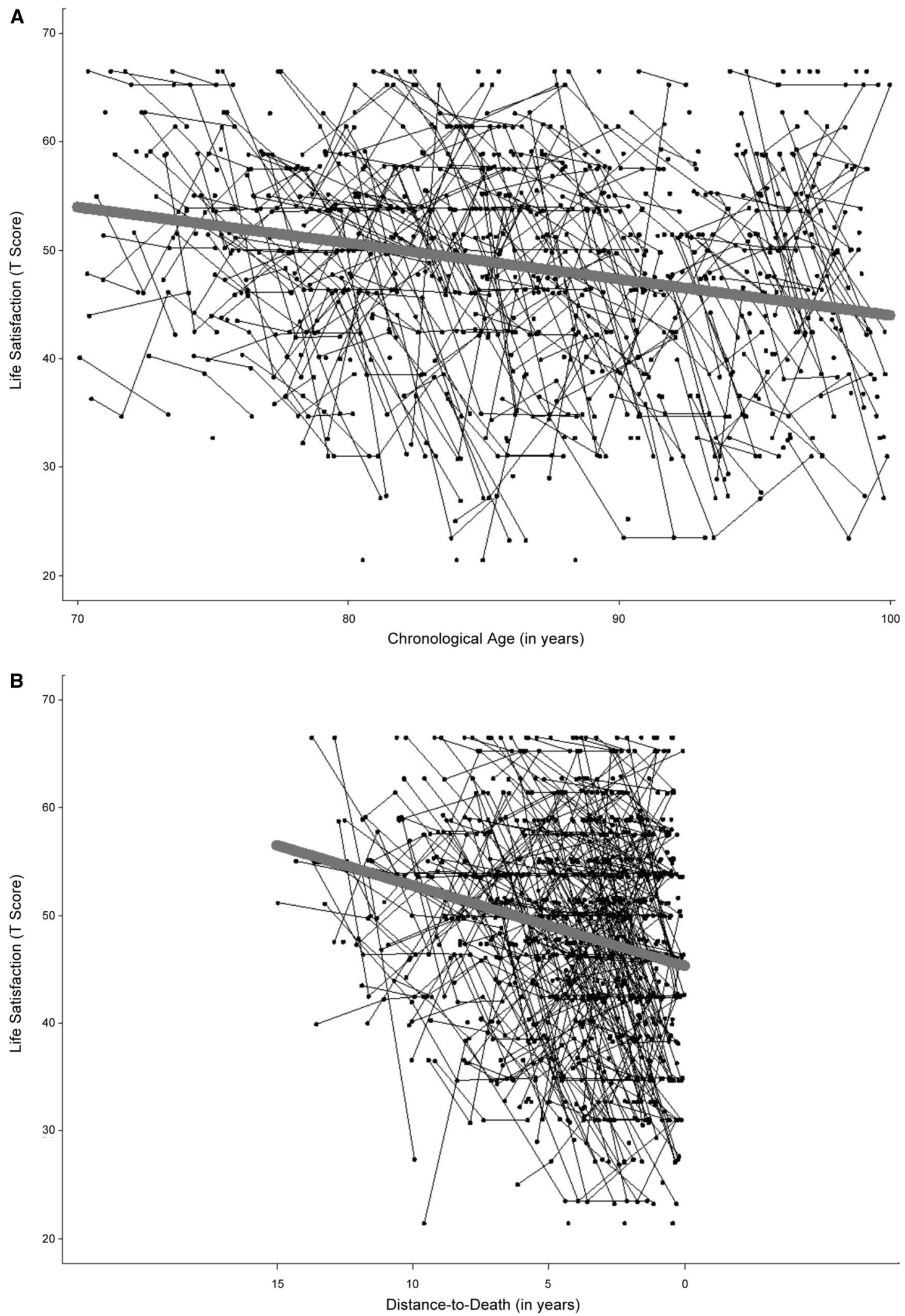

Figure 2. Average amount of decline observed over (A) chronological age and (B) distance-to-death. The age model showed, on average, significant but relatively minor decline $(0.33 \mathrm{~T}$-score units per year). Relative to the age model, decline in the distance-to-death model was steeper by a factor of 2.3 ( $-0.75 \mathrm{~T}$-score units per year). 


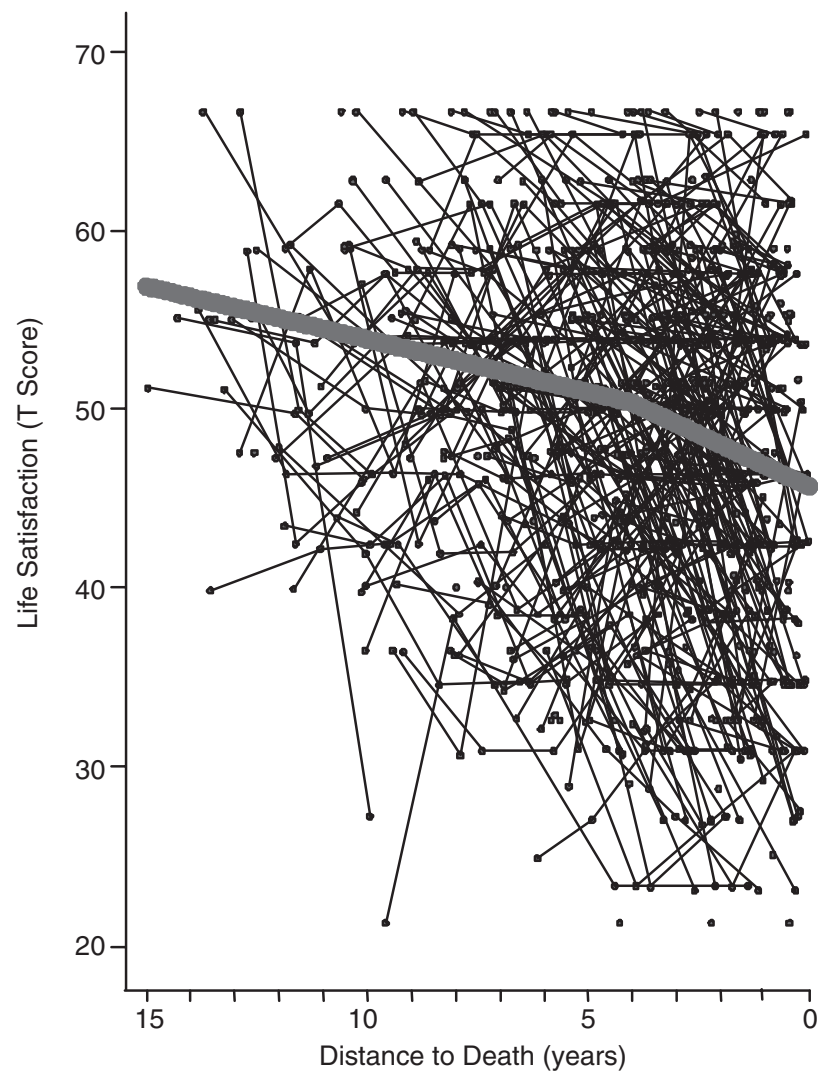

Figure 3. Model-implied means for the optimal change-point model (4 years prior to death) over distance-to-death in life satisfaction. The rate of decline increased from the preterminal phase $(-0.59 \mathrm{~T}$-score units per year) to the terminal phase $(-1.16 \mathrm{~T}$-score units per year) by a factor of 2 .

with the modeled interindividual differences in terminal-phase change. The model took the form

$$
\begin{aligned}
l s_{i t}= & L_{i}+S 1\left(d t d_{i t}\right)+S 2_{i}\left(d t d_{i t}\right)+e_{i t}, \\
& \text { if } d t d_{i t} \leq k=-4.0, \text { then } S 2_{i}=0, \text { and } \\
& \text { if } d t d_{i t} \geq k=-4.0, \text { then } S 1_{i}=0, \text { and where } \\
L_{i}= & \gamma_{L 0}+\gamma_{L 1}\left(\operatorname{age}_{i}\right)+\gamma_{L 2}\left(\operatorname{sex}_{i}\right)+\ldots+u_{L i} \\
S 2_{i}= & \gamma_{S 20}+\gamma_{S 21}\left(\operatorname{age}_{i}\right)+\gamma_{S 22}\left(\operatorname{sex}_{i}\right)+\ldots+u_{S 2 i},
\end{aligned}
$$

where the life satisfaction measure for person $i$ at time $t, l s_{i t}$, is a function of an individual specific intercept parameter, $L_{i}$, a sample specific slope parameter, $S 1$, that captures change over the distance-to-death time dimension, $d t d_{i}$, during the preterminal phase (when $d t d_{i t}<k$ ), an individual-specific slope parameter, $S 2_{i}$, that captures change over the distance-to-death time dimension during the terminal phase (when $d t d_{i t}>k$ ), and residual error, $e_{i t}$. The individual specific intercept and terminal phase slope parameters, $L_{i}$ and $S 2_{i}$, are then each modeled as linear combinations of "fixed effect" parameters $\left(\gamma_{L 0}\right.$ and $\gamma_{S 20}, \gamma_{L 1}$ and $\left.\gamma_{S 21}, \ldots\right)$, associated with (a constant and) various interindividual difference predictors (e.g., age $_{i}, \mathrm{sex}_{i}, \ldots$ ), and unexplained interindividual differences $\left(u_{L i}\right.$ and $\left.u_{S 2 i}\right)$. Specifically, age, sex, SES, comorbidities, dementia status, and perceptual speed were included as pre- dictors of interindividual differences in level, $L_{i}$, and in terminalphase slope, $S 2_{i}$.

Results of these analyses are presented in Table 4. Inspection of parameter estimates for the effects of these variables reveals that of the measures included, only the number of comorbidities was associated with reports of life satisfaction (fixed effect $=$ $-0.18, S E=0.08 ; p<.05)$. None of the covariates included was found to account for significant portions of interindividual differences in terminal-phase decline in life satisfaction.

\section{Follow-Up Analyses}

We also carried out a series of follow-up analyses to substantiate these results. First, rather than using age as a continuous variable, we re-ran the above analysis contrasting youngold (70 years to 84 years at T1) and oldest old individuals (85+ years). Findings indicated that compared with the preterminal slope on life satisfaction (fixed effects of the slope $=-0.59$, $S E=0.14 ; p<.001)$, the terminal slope was only marginally steeper for the young-old (fixed effects of the slope $=-0.68$, $S E=0.42 ; p>.10$ ) but was substantially steeper for the oldest

Table 4

Two-Phase Growth Model Over Distance-to-Death for Life Satisfaction, Change-Point Location at 4 Years Prior to Death: The Effects of Covariates

Parameter Estimate $S$

Fixed effects

Life satisfaction intercept

Life satisfaction preterminal slope (15-4 years)

Life satisfaction terminal slope (4-0 years)

Age

Sex

SES

Comorbidities

$S E$

Dementia

Perceptual speed

Age $\times$ Life Satisfaction terminal slope

Sex $\times$ Life Satisfaction terminal slope

SES $\times$ Life Satisfaction terminal slope

Comorbidities $\times$ Life Satisfaction terminal slope

Dementia $\times$ Life Satisfaction terminal slope

Perceptual Speed $\times$ Life Satisfaction terminal slope

$43.34^{* * * *}$

$-0.59^{\text {*** }}$

$-1.16^{* * *}$

$-0.15$

$-1.29$

0.01

$-0.18$

1.17

0.04

$-0.05$

0.37

$-0.02$

$-0.03$

0.13

$-0.01$

1.26

0.14

0.35

0.12

1.69

0.09

0.08

2.15

0.11

0.03

0.49

0.02

0.02

0.68

0.03

Random effects

Life satisfaction variance of intercept $111.81^{* * * *} \quad 17.18$

Life satisfaction variance of pre-terminal slope

Life satisfaction variance of terminal slope

Life satisfaction covariance intercept, terminal slope

Life satisfaction residual variance

$4.53^{* * *} \quad 1.48$

$15.56^{* * *} \quad 4.66$

$31.34^{* * * *} \quad 2.40$

Goodness-of-fit indices

AIC

$-2 \mathrm{LL}$

6,844

6,806

Note. $\quad N=414$ participants who provided 961 observations. T scores standardized to cross-sectional Berlin Aging Study sample at Time $1(\mathrm{~N}=$ $516, M=50, S D=10)$. Dashes indicate that the life satisfaction variance around the preterminal slope could not be estimated. SES = socioeconomic status; $\mathrm{AIC}=$ Akaike information criterion; $-2 \mathrm{LL}=-2 \log$ likelihood, relative model fit statistics.

${ }^{*} p<.05 .{ }^{* *} p<.01 .{ }^{* * *} p<.001$. 
old (fixed effects of the slope $=-1.71, S E=0.49 ; p<.05$ ), suggesting a threefold increase in the rate of decline between the preterminal phase and the terminal phase for participants aged $85+$ years.

In another set of follow-up analyses, we further explored the uniqueness of the observed terminal decline in life satisfaction in comparison with the previously referenced cognitive terminal decline. For example, if mortality-related decline in life satisfaction was primarily attributable to pronounced cognitive decline with impending death (e.g., preclinical dementia, perceptual speed), we would expect high intercorrelations among these two distance-to-death slope factors. To address this question, first, we included a variable representing cohort-specific cutoffs on the SMMSE at each occasion as time-varying predictors in our models. Both preterminal and terminal slopes on life satisfaction remained significant (fixed effect of the preterminal slope $=-0.60, S E=0.14$, and fixed effects of the terminal slope $=-1.11, S E=0.38$, respectively; $p \mathrm{~s}<.001)$, and the covariances of the SMMSE with the intercept and terminal slope factors were not significantly different from zero (covariance of the intercept $=15.41, S E=14.37$, and covariance of the terminal slope $=4.65, S E=3.08$, respectively; $p$ s $>.10) .{ }^{5}$ Second, we examined correlated (change-point) growth models of life satisfaction and perceptual speed anchored at 4 years prior to death. Although both variables showed pronounced terminal decline (perceptual speed: -1.39 , $S E=0.20$; life satisfaction: $-1.03, S E=0.24, p \mathrm{~s}<.001)$, slope intercorrelations were low and were not significantly different from zero $(r=-.06, p>.10)$. Third and finally, we also used the bivariate latent difference score model of change (McArdle \& Hamagami, 2001) to explore whether mortality-related decline in perceptual speed might precede and predict decline in life satisfaction. These analyses provided no evidence that perceptual speed could be regarded as a leading indicator for terminal decline in life satisfaction. In sum, follow-up analyses indicated that terminal decline effects in life satisfaction in the BASE sample appear to be primarily driven by very old individuals $(85+$ years $)$ and that no evidence was found for a primacy of cognitive terminal decline over mortality-related decline in life satisfaction.

\section{Discussion}

The major objective of the present study was to explore mortality associations of changes in aspects of subjective wellbeing in old and very old age. In a first step, we empirically demonstrated that interindividual differences in intraindividual change in life satisfaction among a subsample of deceased participants of the BASE were better described by distance-todeath rather than by distance-from-birth (chronological age). Indeed, the death-related slope was much steeper than expected on the basis of age-related models. In a second step, we applied change-point growth models to mortality-related change in life satisfaction. These analyses identified a point some 4 years prior to death after which the rate of decline in life satisfaction was steeper by a factor of 2 relative to the preterminal phase. This finding provides empirical evidence that terminal decline phenomena occur in reports of life satisfaction. In a third step, we explored how various mortality predictors were related to late-life changes in life satisfaction. We found that terminal decline in life satisfaction was most pronounced among the oldest old (85+ years), with a threefold increase in the rate of terminal decline relative to the rate of preterminal decline. In contrast, other predictors of mortality, including sex, comorbidities, dementia, and intellectual functioning, accounted for only small portions of interindividual differences in intraindividual terminal change in life satisfaction.

\section{Comparing Age-Related and Mortality-Related Changes in Life Satisfaction}

Our age-related change model suggested relative stability in the average level of life satisfaction. This finding is consistent with previous cross-sectional and longitudinal reports from various large-scale studies that have suggested that well-being remains relatively stable throughout adulthood and old age (Diener et al., 2006; Filipp, 1996; Kunzmann et al., 2000; Larson, 1978; Mroczek \& Kolarz, 1998). In contrast, distance-to-death models of life satisfaction were better representations of interindividual differences in longitudinal change in the BASE data and indicated pronounced average linear decline (approximately double that found in the age-related model) amounting to three quarters of a standard deviation over a 10 -year period. ${ }^{6}$ These results add to the increasing body of literature reporting mortality associations for level of functioning on numerous psychosocial measures including personality (Friedman et al., 1995; Swan \& Carmelli, 1996; Weiss \& Costa, 2005; Wilson, Mendes de Leon, Bienias, Evans, \& Bennett, 2004), feelings of loneliness (Seeman, 2000), selfreported health (Idler \& Benyamini, 1997), and aspects of wellbeing (Danner et al., 2001; Levy et al., 2002; Maier \& Smith, 1999). Whereas in previous studies researchers examined the longterm predictive effects of level of well-being, our results highlight how change in life satisfaction is structured over distance-to-death (see also Mroczek \& Spiro, 2005)—an essential element of terminal decline phenomena.

Our findings provide important qualifications to the literature on well-being across adulthood and into old age (for the effects of major life events on changes in well-being, see Charles, Reynolds, \& Gatz, 2001; Lucas, Clark, Georgellis, \& Diener, 2003, 2004). At the end-of-life, it appears that individuals do find it increasingly difficult to maintain their characteristic level of well-being (Baltes \& Smith, 2003; Diener et al., 2006). The markedly different trajectories revealed by the age-related and death-related models indicate that approaching death encompasses progressive pro-

\footnotetext{
${ }^{5}$ In line with this general pattern, follow-up analyses that included other measures available in the BASE, including initial cognitive functioning (fluency, episodic memory, and verbal knowledge), social losses (of a partner, family member or friend in the year preceding the interview, $n=$ 260; no loss, $n=256$ ), or balance-gait (for details, see Lindenberger \& Baltes, 1997), yielded the same basic pattern of results; that is, the covariates accounted for hardly any of the individual differences in level or change of life satisfaction.

${ }^{6}$ Follow-up analyses revealed that the age gradient for BASE participants who had not died by June $2005(n=83)$ was nominally shallower than those who had died ( -0.28 vs. $-0.33 \mathrm{~T}$-score units per year), but this difference was not statistically significant $(p>.10)$. This lack of a significant difference may reflect the fact that some of the not-yet-deceased participants were relatively close to death and may thus have already entered their mortality-related change trajectory.
} 
cesses that may be distinct from normative age-graded processes. The nominal differences in the rates of decline $(-0.42 \mathrm{~T}$-score units per year) provide a rough quantification of the effects of the processes that precede death on the well-being decline that are added to age-related effects (cf. Sliwinski et al., 2006). That the increased steepness of decline in life satisfaction in the last years of life was not linked to distance-from-birth (i.e., chronological age) but rather to distance-to-death further highlights the importance of explicitly modeling terminal decline. In psychological studies on old age, however, information about how close participants are to their death is often not available. If death-related processes are indeed present, typical age-related examinations conducted in the absence of mortality information may thus misrepresent or mis-specify the change process.

\section{Applying Change-Point Models to Mortality-Related Decline in Life Satisfaction}

In the current study, we took advantage of available city registry information for date of death and applied a change-point growth method that enabled us to model multiple phases of change (e.g., Hall et al., 2000). Although the size of the standard error around the change point did not allow for an exact estimate of the location of the change point, statistically nested model comparisons isolated a time interval between 2 years and 6 years prior to death during which a transition from a preterminal to a terminal phase of decline in life satisfaction might occur. The rate of preterminal decline was already stronger than expected on the basis of the age models, and this rate of decline was steeper by a factor of 2 in the terminal phase. Empirical evidence for the existence of multiple phases in mortality-related change has so far been reported from measures of cognitive functioning including perceptual speed and memory (Sliwinski et al., 2006; Wilson et al., 2003, 2007). To the best of our knowledge, this study is the first to demonstrate that a substantially steeper decline in the last years of life extends to aspects of well-being. The general time interval identified overlaps with and is roughly consistent with findings from the cognitive domain. We note, however, that in light of the scarcity of theoretical propositions about the most likely change point, the location of the transition to an increased steepness of decline has so far been determined by empirical means only. Thus, it seems that the field is still in an exploratory mode, and future studies are required to examine the generalizability of these findings (e.g., with a less positively selected population-based sample). For example, initial evidence from the nationally representative German SocioEconomic Panel Study (see Gerstorf, Ram, Estabrook, Schupp, Wagner, \& Lindenberger, 2007) could replicate and extend the general pattern of results as found in the BASE.

We acknowledge that any application of change-point models, similar to other multivariate-structural analyses, is based on some untested statistical assumptions, including ergodicity (Molenaar, Huizenga, \& Nesselroade, 2003) and sample homogeneity (Borsboom, Mellenbergh, \& van Heerden, 2003). For example, our average results (and those of other studies) are population level estimates and do not necessarily represent changes occurring within a given individual. Similarly, in our analysis, the change point between the preterminal and the terminal phase was specified as a population parameter with no variance (e.g., fixed effect), reflecting the strong assumption that the location of the change point is invariant across individuals. The limited number and density of longitudinal observations in BASE in relation to distance-to-death did not allow a determination of change points at the individual level. In future research, random effect change-point models should be examined to explore, for example, whether mortality-related decline on facets of well-being may be characterized by an acute terminal drop for some (groups of) individuals but a more protracted decline for others (see also Bäckman \& MacDonald, 2006). Taken together, however, our results do provide further support for the terminal decline hypothesis that imminent death in very old age may have pervasive effects across domains of functioning and do provide a quantitative description of the onset, extent, and temporal course of terminal decline in life satisfaction.

\section{Exploring Potential Factors Underlying Mortality-Related Decline in Life Satisfaction}

We explored the role of established mortality predictors (Anstey et al., 2006; Berkman, 1988; Johansson \& Zarit, 1997) to account for individual differences in mortality-related change in life satisfaction. Although chronological age, per se, did not account for terminal decline in life satisfaction, the effect was most pronounced among participants older than age $85+$ years, with a threefold increase in the rate of decline from the preterminal to the terminal phase. Their rate of mortality-related decline was approximately doubled relative to young-old individuals, suggesting that the additional burden of approaching death appears to be especially pronounced among the very old. In this regard, our results are consistent with the view that the oldest old are at the limits of their adaptive capacity (Baltes \& Smith, 2003; Smith \& Gerstorf, 2004). The system of self-protective processes associated with the maintenance of well-being appears to become increasingly vulnerable. This is also in line with criticisms of the Riegel and Riegel (1972) hypothesis in the cognitive aging literature (see Bäckman \& MacDonald, 2006), which had originally stated that the effects of terminal decline may diminish in late senescence due to more random causes of death.

One scenario in the literature about the possible temporal effects of the other mortality predictors examined is a sequence of steps involving an initial decline in, for example, intellectual functioning (as represented by perceptual speed as the most powerful indicator of mortality-related cognitive decline), followed by a decline in subjective well-being and, finally, death (cf. Maier \& Smith, 1999). With this scenario in mind, we were somewhat surprised that (with the exception of age group) none of the factors examined was associated with individual variation in mortality-related decline on life satisfaction. Additional follow-up analyses also indicated a low intercorrelation between cognitive terminal decline and terminal decline in life satisfaction, suggesting that these processes show very little overlap. We acknowledge, however, that lack of statistical power may have made it difficult to provide definitive answers regarding cross-domain links. Hertzog, Lindenberger, Ghisletta, and von Oertzen (2006) demonstrated that even with large samples $(N=500)$ and six measurement occasions, as in the present study, statistical power to detect slope correlations between two variables is moderate to low, unless growth curve reliability at study onset was above .90 . In a similar vein, one constraint in our multiphase models is that the variance component in the preterminal decline phase was nonsignificant, thereby precluding inferences regarding the intercorrelations of decline in the 
preterminal and terminal phase. It would have been instructive to examine the extent to which individual differences in change within each phase relate across phases.

Leaving issues of statistical power aside, the present analyses reveal that terminal decline in life satisfaction cannot completely be attributed to factors that broadly represent past, cumulative, and current developmental contexts or conditions that are pathological in nature, such as moderate to severe chronic illnesses at baseline assessment and preclinical dementia over time. Furthermore, our findings are consistent with notions that much of the observed change in advanced old age is stochastic and reflects the incomplete biogenetic architecture of ontogeny (Baltes, 1997; Finch \& Kirkwood, 2000; Thaler, 2002). Johansson et al. (2004), for example, reported increased heterogeneity in timing and rates of mortality-related cognitive decline among genetically identical twins aged 80 years and older. In this context, we acknowledge that more in-depth studies are needed to specifically pinpoint potential sources of inter- and intraindividual variability in the timing and the onset of mortality associated decline in well-being. Although research suggests that cognitive decline is relatively independent of cause of death (e.g., Anstey et al., 2006; Small et al., 2003), it is conceivable that various causes of death in very old age (e.g., cerebrovascular, cardiac, frailty, and cancer) and conditions associated with the process of dying may account for differential portions of individual differences in terminal decline of well-being. The present data did not allow an examination of these speculations.

Conceptually, it is an open question as to what underlies the pronounced deterioration of well-being linked to death and interindividual differences therein. To avoid a possible misunderstanding of our findings, it is important to note that we certainly do not contend that changes in well-being constitute a major source of mortality. Instead, well-being ratings might represent evaluations that reflect quite accurate summary perceptions of an individual's level of and change in functioning in a variety of domains (Maier \& Smith, 1999) or an individual's will-to-live (Jopp \& Rott, 2006; Lawton et al., 1999). Increasingly negative life evaluations may not be directly related to mortality but rather reflect potential causes from other domains (e.g., health or biological functioning) that we have not captured in this study. From another perspective, however, aspects of well-being might be key factors for preserved functioning in other domains that more directly relate to mortality. For example, several authors have pointed to the physiological effects of positive or negative self-perceptions of one's life and aging with regard to cardiovascular and immune functioning as well as recovery after heart attack (Danner et al., 2001; KiecoltGlaser, McGuire, Robles, \& Glaser, 2002; Pressman \& Cohen, 2005; Steptoe, Wardle, \& Marmot, 2005). Such physiological effects could also influence the brain and thus have an impact on subsequent functioning and long-term survival. Similarly, wellbeing might relate to mortality by having profound motivational and behavioral consequences (e.g., engagement and persistence), which in turn either restrain or help to exploit an individual's resources in the long run (Furry \& Baltes, 1973; Levy et al., 2002).

\section{Conclusions and Outlook}

Our findings, gathered from 414 decedents of the BASE, indicated that an exacerbated rate of decline in the last years of life may not be specific to intellectual and sensory functioning, but may also extend to subjective well-being. Whereas the White and Cunningham (1988) hypothesis of steeper mortality-related decline in relatively age-insensitive measures has been largely refuted for cognitive abilities (cf. Bäckman \& MacDonald, 2006), our results suggest that it may apply to other areas of psychological functioning, especially self-related dimensions. Proximity to death may bring about not only greater losses than expected in agesensitive domains, such as multiple facets of cognitive functioning, but also substantial decline in domains of functioning, such as a sense of well-being, that are usually well preserved into old and advanced old age.

Our findings warrant more in-depth analyses in future studies. One open question is whether the terminal decline phenomenon extends to other psychosocial variables. It would be instructive to examine whether emotion-based measures of well-being, aspects of personality, self-reported health, or feelings of loneliness, all of which have been identified as long-term predictors of mortality, also show distinctively different trajectories of change over age and distance-to-death in old age. It would also be worthwhile to examine to what extent terminal decline entails qualitative changes in structure or cascading effects across domains of functioning (Birren \& Cunningham, 1985; Siegler, 1975). In addition, individual differences in intraindividual variation in subjective well-being represent a persistent phenomenon not only across years but across much shorter time frames as well, such as days and months (e.g., Eid \& Diener, 1999; Nesselroade \& Featherman, 1997; Röcke, 2006). A route worth exploring in future studies would be to extend the findings of the present article to include an examination of the role of mortality-related changes over and above age-related changes in longer term trajectories of short-term variability in well-being. The increase of losses associated with advanced old age may bring about not only a steady increase but a sudden increase in variability in the oldest old, possibly indicating a terminal decline in the capacity of the psychological system to sustain equilibrium and regulation (e.g., Eizenman, Nesselroade, Featherman, \& Rowe, 1997; Thaler, 2002). Intensive multivariate longitudinal assessments of collections of individuals from earlyto-old age to advanced old age are needed to separate and integrate the operation of age-related, death-related, and pathology-related mechanisms on changes in the organization of psychological functioning during the last phase of life (Jones \& Nesselroade, 1990).

\section{References}

Anstey, K., Mack, H. A., \& von Sanden, C. (2006). The relationship between cognition and mortality in patients with stroke, coronary heart disease, or cancer. European Psychologist, 11, 182-195.

Bäckman, L., \& MacDonald, S. W. S. (2006). Death and cognition: Synthesis and outlook. European Psychologist, 11, 224-235.

Baltes, P. B. (1997). On the incomplete architecture of human ontogeny: Selection, optimization, and compensation as foundation of developmental theory. American Psychologist, 52, 366-380.

Baltes, P. B., \& Baltes, M. M. (Eds.). (1990). Successful aging: Perspectives from the behavioral sciences. New York: Cambridge University Press.

Baltes, P. B., \& Mayer, K. U. (Eds.). (1999). The Berlin Aging Study: Aging from 70 to 100. New York: Cambridge University Press.

Baltes, P. B., \& Smith, J. (1997). A systemic-wholistic view of psychological functioning in very old age: Introduction to a collection of articles from the Berlin Aging Study. Psychology and Aging, 12, 395409 . 
Baltes, P. B., \& Smith, J. (2003). New frontiers in the future of aging: From successful aging of the young old to the dilemmas of the fourth age. Gerontology, 49, 123-135.

Berg, S. (1996). Aging, behavior, and terminal decline. In J. E. Birren \& K. W. Schaie (Eds.), Handbook of the psychology of aging (4th ed., pp. 323-337). San Diego, CA: Academic Press.

Berkman, L. F. (1988). The changing and heterogeneous nature of aging and longevity: A social and biomedical perspective. In G. L. Maddox \& M. P. Lawton (Eds.), Annual review of gerontology and geriatrics: Varieties of aging (Vol. 8, pp. 37-68). New York: Springer.

Birren, J. E., \& Cunningham, W. (1985). Research on the psychology of aging: Principles, concepts, and theory. In J. E. Birren \& K. W. Schaie (Eds.), Handbook of the psychology of aging (2nd ed., pp. 3-34). New York: Van Nostrand Reinhold

Borsboom, D., Mellenbergh, G. J., \& van Heerden, J. (2003). The theoretical status of latent variables. Psychological Review, 110, 203-219.

Bosworth, H. B., \& Schaie, K. W. (1999). Survival effects in cognitive function, cognitive style, and sociodemographic variables in the Seattle Longitudinal Study. Experimental Aging Research, 25, 121-139.

Bosworth, H. B., \& Siegler, I. C. (2002). Terminal change in cognitive function: An updated review of longitudinal studies. Experimental Aging Research, 28, 299-315.

Bryk, A. S., \& Raudenbush, S. W. (1992). Hierarchical linear models in social and behavioral research: Applications and data analysis methods. Newbury Park, CA: Sage

Charles, S. T., Reynolds, C. A., \& Gatz, M. (2001). Age-related differences and change in positive and negative affect over 23 years. Journal of Personality and Social Psychology, 80, 136-151.

Cudeck, R., \& Klebe, K. J. (2002). Multiphase mixed-effects model for repeated measure data. Psychological Methods, 7, 41-63.

Danner, D. D., Snowdon, D. A., \& Friesen, W. V. (2001). Positive emotions in early life and longevity: Findings from the Nun Study. Journal of Personality and Social Psychology, 80, 804-813.

Diener, E., Lucas, R. E., \& Scollon, C. N. (2006). Beyond the hedonic treadmill: Revising the adaptation theory of well-being. American Psychologist, 61, 305-314.

Eid, M., \& Diener, E. (1999). Intraindividual variability in affect: Reliability, validity, and personality correlates. Journal of Personality and Social Psychology, 76, 662-676.

Eizenman, D. R., Nesselroade, J. R., Featherman, D. L., \& Rowe, J. W. (1997). Intraindividual variability in perceived control in an older sample: The MacArthur Successful Aging Studies. Psychology and Aging, 12, 489-502.

Filipp, S. H. (1996). Motivation and emotion. In J. E. Birren \& K. W. Schaie (Eds.), Handbook of the psychology of aging (4th ed., pp. 218-235). San Diego, CA: Academic Press.

Finch, C. E., \& Kirkwood, T. B. L. (2000). Chance, development, and aging. New York: Oxford University Press.

Friedman, H. S., Tucker, J. S., Schwartz, J. E., Tomlinson-Keasey, C., Martin, L. R., Wingard, D. L., et al. (1995). Psychosocial and behavioral predictors of longevity: The aging and death of the "Termites." American Psychologist, 50, 69-78.

Furry, C. A., \& Baltes, P. B. (1973). The effect of age differences in ability-extraneous performance variables on the assessment of intelligence in children, adults, and the elderly. Journal of Gerontology, 28, 73-80.

Gerstorf, D., Herlitz, A., \& Smith, J. (2006). Stability of sex differences in cognition in advanced old age: The role of education and attrition. Journals of Gerontology, Series B: Psychological Sciences and Social Sciences, 61, P245-P249.

Gerstorf, D., Lövdén, M., Röcke, C., Smith, J., \& Lindenberger, U. (2007). Well-being affects changes in perceptual speed in advanced old age: Longitudinal evidence for a dynamic link. Developmental Psychology, 43, 705-718.

Gerstorf, D., Ram, N., Estabrook, R., Schupp, J., Wagner, G. G., \&
Lindenberger, U. (2007). Life satisfaction shows terminal decline in old age: Longitudinal evidence from the German Socioeconomic Panel Study. Manuscript submitted for publication.

Ghisletta, P., McArdle, J. J., \& Lindenberger, U. (2006). Longitudinal cognition-survival relations in old and very old age: 13-year data from the Berlin Aging Study. European Psychologist, 11, 204-223.

Guralnik, J. M. (1991). Prospects for the compression of morbidity: The challenge posed by increasing disability in the years prior to death. Journal of Aging and Health, 3, 138-154.

Hall, C. B., Lipton, R. B., Sliwinski, M. J., \& Stewart, W. F. (2000). A change point model for estimating the onset of cognitive decline in preclinical Alzheimer's disease. Statistics in Medicine, 19, 1555-1566.

Hassing, L. B., Johansson, B., Berg, S., Nilsson, S. E., Pedersen, N. L., Hofer, S. M., et al. (2002). Terminal decline and markers of cerebro- and cardiovascular disease: Findings from a longitudinal study of the oldest old. Journals of Gerontology, Series B: Psychological Sciences and Social Sciences, 57, P268-P276.

Helmchen, H., Baltes, M. M., Geiselmann, B., Kanowski, S., Linden, M., Reischies, F. M., et al. (1999). Psychiatric illnesses in old age. In P. B. Baltes \& K. U. Mayer (Eds.), The Berlin Aging Study: Aging from 70 to 100 (pp. 167-196). New York: Cambridge University Press.

Hertzog, C., Lindenberger, U., Ghisletta, P., \& von Oertzen, T. (2006). On the power of multivariate latent growth curve models to detect correlated change. Psychological Methods, 11, 244-252.

Hofer, S. M., Christensen, H., Mackinnon, A. J., Korten, A. E., Jorm, A. F., Henderson, A. S., et al. (2002). Change in cognitive functioning associated with ApoE genotype in a community sample of older adults. Psychology and Aging, 17, 194-208.

Idler, E. L., \& Benyamini, Y. (1997). Self-rated health and mortality: A review of twenty-seven community studies. Journal of Health and Social Behavior, 38, 21-37.

Johansson, B., Hofer, S. M., Allaire, J. C., Maldonado-Molina, M. M., Piccinin, A. M., Berg, S., et al. (2004). Change in cognitive capabilities in the oldest old: The effects of proximity to death in genetically related individuals over a 6-year period. Psychology and Aging, 19, 145-156.

Johansson, B., \& Zarit, S. H. (1997). Early cognitive markers of the incidence of dementia and mortality: A longitudinal population-based study of the oldest old. International Journal of Geriatric Psychiatry, 12, 53-59.

Jones, C. J., \& Nesselroade, J. R. (1990). Multivariate, replicated, singlesubject, repeated measures designs and p-technique factor analysis: A review of intraindividual change studies. Experimental Aging Research, 16, 171-183.

Jopp, D., \& Rott, C. (2006). Adaptation in very old age: Exploring the role of resources, beliefs, and attitudes for centenarians' happiness. Psychology and Aging, 21, 266-280.

Kiecolt-Glaser, J. K., McGuire, L., Robles, T. F., \& Glaser, R. (2002). Emotions, morbidity, and mortality: New perspectives from psychoneuroimmunology. Annual Review of Psychology, 53, 83-107.

Kleemeier, R. W. (1962). Intellectual changes in the senium. Proceedings of the Social Statistics Section of the American Statistical Association, 1, 290-295.

Klein, L. E., Roca, R. P., McArthur, J., Vogelsang, G., Klein, G. B., Kirby, S. M., et al. (1985). Diagnosing dementia. Univariate and multivariate analyses of the mental status examination. Journal of the American Geriatrics Society, 33, 483-488.

Kunzmann, U., Little, T. D., \& Smith, J. (2000). Is age-related stability of subjective well-being a paradox? Cross-sectional and longitudinal evidence from the Berlin Aging Study. Psychology and Aging, 15, 511526.

Larson, R. (1978). Thirty years of research on the subjective well-being of older Americans. Journal of Gerontology, 33, 109-125.

Laukka, E. J., MacDonald, S. W. S., \& Bäckman, L. (2006). Contrasting cognitive trajectories of impending death and preclinical dementia in the very old. Neurology, 66, 833-838. 
Lawton, M. P. (1975). The Philadelphia Geriatric Center Morale Scale: A revision. Journal of Gerontology, 30, 85-89.

Lawton, M. P., Moss, M., Hoffman, C., Grant, R., Ten Have, T., \& Kleban, M. H. (1999). Health, valuation of life, and the wish to live. Gerontologist, 39, 406-416.

Levy, B. R., Slade, M. D., Kunkel, S. R., \& Kasl, S. V. (2002). Longevity increased by positive self-perceptions of aging. Journal of Personality and Social Psychology, 83, 261-270.

Liang, J., \& Bollen, K. A. (1983). The structure of the Philadelphia Geriatric Center Morale Scale: A reinterpretation. Journal of Gerontology, 38, 181-189.

Lindenberger, U., \& Baltes, P. B. (1997). Intellectual functioning in old and very old age: Cross-sectional results from the Berlin Aging Study. Psychology and Aging, 12, 410-432.

Lindenberger, U., Gilberg, R., Little, T. D., Nuthmann, R., Pötter, U., \& Baltes, P. B. (1999). Sample selectivity and generalizability of the results of the Berlin Aging Study. In P. B. Baltes \& K. U. Mayer (Eds.), The Berlin Aging Study: Aging from 70 to 100 (pp. 56-82). New York: Cambridge University Press.

Lindenberger, U., Singer, T., \& Baltes, P. B. (2002). Longitudinal selectivity in aging populations: Separating mortality-associated versus experimental components in the Berlin Aging Study (BASE). Journals of Gerontology, Series B: Psychological Sciences and Social Sciences, 57, P474-P482.

Littell, R. C., Miliken, G. A., Stoup, W. W., \& Wolfinger, R. D. (1996). SAS system for mixed models. Cary, NC: SAS Institute.

Little, R. J. A., \& Rubin, D. B. (1987). Statistical analysis with missing data. New York: Wiley.

Lucas, R. E., Clark, A. E., Georgellis, Y., \& Diener, E. (2003). Reexamining adaptation and the set point model of happiness: Reactions to changes in marital status. Journal of Personality and Social Psychology, $84,527-539$.

Lucas, R. E., Clark, A. E., Georgellis, Y., \& Diener, E. (2004). Unemployment alters the set point for life satisfaction. Psychological Science, $15,8-13$.

Lyubomirsky, S., King, L., \& Diener, E. (2005). The benefits of frequent positive affect: Does happiness lead to success? Psychological Bulletin, 131, 803-855.

Lyyra, T. M., Törmäkangas, T. M., Read, S., Rantanen, T., \& Berg, S. (2006). Satisfaction with present life predicts survival in octogenarians. Journals of Gerontology, Series B: Psychological Sciences and Social Sciences, 61, P319-P326.

Maier, H., \& Smith, J. (1999). Psychological predictors of mortality in old age. Journals of Gerontology, Series B: Psychological Sciences and Social Sciences, 54, P44-P54.

Mayer, K. U., Maas, I., \& Wagner, M. (1999). Socioeconomic conditions and social inequalities in old age. In P. B. Baltes \& K. U. Mayer (Eds.), The Berlin Aging Study: Aging from 70 to 100 (pp. 227-258). New York: Cambridge University Press.

McArdle, J. J., \& Hamagami, F. (2001). Latent difference score structural models for linear dynamic analyses with incomplete longitudinal data. In L. M. Collins \& A. G. Sayer (Eds.), New methods for the analysis of change (pp. 137-176). Washington, DC: American Psychological Association.

McArdle, J. J., \& Nesselroade, J. R. (2003). Growth curve analysis in contemporary psychological research. In J. Shinka \& W. Velicer (Eds.), Comprehensive handbook of psychology: Research methods in psychology (Vol. 2, pp. 447-480). New York: Wiley.

Molenaar, P. C. M., Huizenga, H. M., \& Nesselroade, J. R. (2003). The relationship between the structure of interindividual and intraindividual variability: A theoretical and empirical vindication of developmental systems theory. In U. M. Staudinger \& U. Lindenberger (Eds.), Understanding human development. Dialogues with lifespan psychology (pp. 339-360). Dordrecht, the Netherlands: Kluwer Academic.

Mroczek, D. K., \& Kolarz, C. M. (1998). The effect of age on positive and negative affect: A developmental perspective on happiness. Journal of Personality and Social Psychology, 75, 1333-1349.

Mroczek, D. K., \& Spiro, A., III. (2003). Modeling intraindividual change in personality traits: Findings from the Normative Aging Study. Journals of Gerontology, Series B: Psychological Sciences and Social Sciences, 58, P153-P165.

Mroczek, D. K., \& Spiro, A., III. (2005). Change in life satisfaction during adulthood: Findings from the Veterans Affairs Normative Aging Study. Journal of Personality and Social Psychology, 88, 189-202.

Nesselroade, J. R., \& Featherman, D. L. (1997). Establishing a reference frame against which to chart age-related changes. In M. A. Hardy (Ed.), Studying aging and social change: Conceptual and methodological issues (pp. 191-205). Thousand Oaks, CA: Sage.

Nussbaum, P. D. (1997). Late-life depression: A neuropsychological perspective. In P. D. Nussbaum (Ed.), Handbook of neuropsychology and aging (pp. 260-270). New York: Plenum Press.

Palmore, E., \& Cleveland, W. (1976). Aging, terminal decline, and terminal drop. Journal of Gerontology, 31, 76-81.

Pressman, S. D., \& Cohen, S. (2005). Does positive affect influence health?. Psychological Bulletin, 131, 925-971.

Rabbitt, P., Watson, P., Donlan, C., McInnes, L., Horan, M., Pendleton, N., et al. (2002). Effects of death within 11 years on cognitive performance in old age. Psychology and Aging, 17, 468-481.

Riegel, K. F., \& Riegel, R. M. (1972). Development, drop, and death. Developmental Psychology, 6, 306-419.

Röcke, C. (2006). Intraindividual variability in positive and negative affect: Age-related and individual differences in magnitude and coupling with cognitive performance. Unpublished doctoral dissertation. Free University Berlin, Berlin, Germany.

Rowe, J. W., \& Kahn, R. L. (1997). Successful aging. Gerontologist, 37, 433-440.

Ryff, C. D., \& Singer, B. (1998). The contours of positive human health. Psychological Inquiry, 9, 1-28.

Seeman, T. E. (2000). Health promoting effects of friends and family on health outcomes in older adults. American Journal of Health Promotion, 14, 362-370.

Siegler, I. C. (1975). The terminal drop hypothesis: Fact or artifact? Experimental Aging Research, 1, 169-185.

Singer, J. D., \& Willett, J. B. (2003). Applied longitudinal data analysis: Modeling change and event occurrence. New York: Oxford University Press.

Sliwinski, M. J., Hofer, S. M., Hall, C., Buschke, H., \& Lipton, R. B. (2003). Modeling memory decline in older adults: The importance of preclinical dementia, attrition, and chronological age. Psychology and Aging, 18, 658-671.

Sliwinski, M. J., Stawski, R. S., Hall, R. B., Katz, M., Verghese, J., \& Lipton, R. B. (2006). On the importance of distinguishing pre-terminal and terminal cognitive decline. European Psychologist, 11, 172-181.

Small, B. J., \& Bäckman, L. (1999). Time to death and cognitive performance. Current Directions in Psychological Science, 8, 168-172.

Small, B. J., Fratiglioni, L., von Strauss, E., \& Bäckman, L. (2003). Terminal decline and cognitive performance in very old age: Does cause of death matter? Psychology and Aging, 18, 193-202.

Smith, J., \& Delius, J. A. M. (2003). Die längsschnittlichen Erhebungen der Berliner Altersstudie (BASE): Design, Stichproben und Schwerpunkte 1990-2002 [The longitudinal assessments in the Berlin Aging Study (BASE): Design, samples, and topics 1990-2002]. In F. Karl (Ed.), Sozial- und verhaltenswissenschaftliche Gerontologie: Alter und Altern als gesellschaftliches Problem und individuelles Thema (pp. 225-249). Weinheim, Germany: Juventa.

Smith, J., Fleeson, W., Geiselmann, B., Settersten, R. A., Jr., \& Kunzmann, U. (1999). Sources of well-being in very old age. In P. B. Baltes \& K. U. Mayer (Eds.), The Berlin Aging Study: Aging from 70 to 100 (pp. 450-471). New York: Cambridge University Press.

Smith, J., \& Gerstorf, D. (2004). Aging differently: Potentials and limits. 
In S. O. Daatland \& S. Biggs (Eds.), Ageing and diversity: Multiple pathways and cultural migrations (pp. 13-28). Bristol, England: Policy Press.

Smith, J., Maas, I., Mayer, K. U., Helmchen, H., Steinhagen-Thiessen, E., \& Baltes, P. B. (2002). Two-wave longitudinal findings from the Berlin Aging Study: Introduction to a collection of articles. Journals of Gerontology, Series B: Psychological Sciences and Social Sciences, 57, P471-P473.

Snijders, T. A. B., \& Bosker, R. J. (1999). Multilevel analysis: An introduction to basic and advanced multilevel modeling. London, England: Sage.

Steinhagen-Thiessen, E., \& Borchelt, M. (1999). Morbidity, medication, and functional limitations in very old age. In P. B. Baltes \& K. U. Mayer (Eds.), The Berlin Aging Study: Aging from 70 to 100 (pp. 131-166). New York: Cambridge University Press.

Steptoe, A., Wardle, J., \& Marmot, M. (2005). Positive affect and healthrelated neuroendocrine, cardiovascular, and inflammatory processes. Proceedings of the National Academy of Sciences, USA, 102, 65086512.

Swan, G. E., \& Carmelli, D. (1996). Curiosity and mortality in aging adults: A 5-year follow-up of the Western Collaborative Group Study. Psychology and Aging, 11, 449-453.

Thaler, D. S. (2002). Design for an aging brain. Neurobiology of Aging, 23, $13-15$.

Wechsler, D. (1982). Handanweisung zum Hamburg-Wechsler-
Intelligenztest fuer Erwachsene (HAWIE) [Manual for the Hamburg Wechsler Intelligence Tests for Adults]. Bern, Switzerland: Huber.

Weiss, A., \& Costa Jr., P. T. (2005). Domain and facet personality predictors of all-cause mortality among Medicare patients aged 65 to 100. Psychosomatic Medicine, 67, 724-733.

White, N., \& Cunningham, W. R. (1988). Is terminal drop pervasive or specific? Journals of Gerontology, Series B: Psychological Sciences and Social Sciences, 43, P141-P144.

Wilson, R. S., Beck, T. L., Bienias, J. L., \& Bennett, D. A. (2007) Terminal cognitive decline: Accelerated loss of cognition in the last years of life. Psychosomatic Medicine, 69, 131-137.

Wilson, R. S., Beckett, L. A., Bienias, J. L., Evans, D. A., \& Bennett, D. A (2003). Terminal decline in cognitive function. Neurology, 60, 17821787.

Wilson, R. S., Mendes de Leon, C. F., Bienias, J. L., Evans, D. A., \& Bennett, D. A. (2004). Personality and mortality in old age. Journals of Gerontology, Series B: Psychological Sciences and Social Sciences, 59, P110-P116.

World Health Organization. (1992). International classification of diseases (9th ed.). Geneva, Switzerland: Author.

Received February 9, 2007

Revision received May 23, 2007

Accepted July 3, 2007 